\title{
Safety, Tolerability, and Pharmacokinetics of Etamicastat, a Novel Dopamine- $\beta$ - Hydroxylase Inhibitor, in a Rising Multiple-Dose Study in Young Healthy Subjects
}

\author{
Teresa Nunes, ${ }^{1}$ José F. Rocha, ${ }^{1}$ Manuel Vaz-da-Silva, ${ }^{1}$ Bruno Igreja,${ }^{1}$ Lyndon C. Wright, ${ }^{1}$ \\ Amílcar Falcão, ${ }^{2}$ Luis Almeida ${ }^{3}$ and Patricio Soares-da-Silva $a^{1,4}$ \\ 1 Department of Research and Development, BIAL-Portela and Co., SA, S. Mamede do Coronado, Portugal \\ 2 4Health Ltd, Cantanhede, Portugal \\ 3 Health Sciences Section, University of Aveiro, Aveiro, Portugal \\ 4 Institute of Pharmacology and Therapeutics, Faculty of Medicine, University of Porto, Porto, Portugal
}

\section{Abstract}

Background: Activation of the sympathetic nervous system is an important feature in hypertension and congestive heart failure. A strategy for directly modulating sympathetic nerve function is to reduce the biosynthesis of norepinephrine (noradrenaline) via inhibition of dopamine- $\beta$-hydroxylase $(\mathrm{D} \beta \mathrm{H})$. Objective: To assess the safety, tolerability, and pharmacokinetics of etamicastat (BIA 5-453), a new D $\beta \mathrm{H}$ inhibitor, following repeated dosing.

Methods: A double-blind, randomized, placebo-controlled study was conducted in healthy young male volunteers. Participants received once-daily doses of placebo or etamicastat 25, 50,100, 200, 400, or $600 \mathrm{mg}$, for 10 days. Results: Etamicastat underwent N-acetylation to its metabolite BIA 5-961. Etamicastat and BIA 5-961 maximum concentrations were achieved at 1-3 and 2-4 hours, respectively, after dosing. Elimination half-lives ranged from 18.1 to 25.7 hours for etamicastat and 6.7 to 22.5 hours for BIA 5-961. Both etamicastat and BIA 5-961 followed linear pharmacokinetics. The extent of systemic exposure to etamicastat and BIA 5-961 increased in an approximately dose-proportional manner, and steady-state plasma concentrations were attained up to 9 days of dosing. Etamicastat accumulated in plasma following repeated administration. The mean observed accumulation ratio was 1.3-1.9 for etamicastat and 1.3-1.6 for BIA 5-961. Approximately $40 \%$ of the etamicastat dose was recovered in urine in the form of parent compound and BIA 5-961. There was a high variability in pharmacokinetic parameters, attributable to different N-acetyltransferase-2 (NAT2) phenotype. Urinary excretion of norepinephrine decreased following repeated administration of etamicastat. Etamicastat was generally well tolerated. There was no serious 
adverse event or clinically significant abnormality in clinical laboratory tests, vital signs, or ECG parameters.

Conclusion: Etamicastat was well tolerated. Etamicastat undergoes N-acetylation, which is markedly influenced by NAT2 phenotype. NAT2 genotyping could be a step toward personalized medicine for etamicastat.

Trial Registration: EudraCT No. 2007-004142-33

\section{Background}

Activation of the sympathetic nervous system is a common finding in congestive heart failure and hypertension. ${ }^{[1-6]}$ Adrenoceptor antagonists can be used to inhibit such sympathetic activation, but a proportion of patients do not tolerate the immediate hemodynamic impact, particularly in heart failure. ${ }^{[7]}$ An alternative strategy is to inhibit dopamine- $\beta$-hydroxylase (D $\beta \mathrm{H} ; \mathrm{EC}$ 1.14.17.1), a mono-oxygenase that catalyses the conversion of dopamine into norepinephrine (noradrenaline) in the catecholamine biosynthetic pathway. ${ }^{[8]}$ Gradual sympathetic modulation by $\mathrm{D} \beta \mathrm{H}$ inhibitors as opposed to abrupt inhibition observed with $\beta$-adrenoceptor blockers ( $\beta$-blockers) could decrease the hemodynamic negative impact. ${ }^{[9]}$ Furthermore, inhibition of $\mathrm{D} \beta \mathrm{H}$ also increases dopamine release, ${ }^{[10,11]}$ which can improve renal function by causing renal vasodilatation and inducing diuresis and natriuresis. ${ }^{[9,12,13]}$

Several $\mathrm{D} \beta \mathrm{H}$ inhibitors have been thus far reported:[14-16] however, both first- and secondgeneration $\mathrm{D} \beta \mathrm{H}$ inhibitors were found to have low potency, poor $\mathrm{D} \beta \mathrm{H}$ selectivity, and relevant toxic effects. ${ }^{[17]}$ Nepicastat (RS-25560-197), ${ }^{[8]}$ a third-generation $\mathrm{D} \beta \mathrm{H}$ inhibitor, was found to have much greater potency and to be devoid of some of the problems associated with first- and second-generation inhibitors. However, nepicastat was found to cross the blood-brain barrier and to cause potentially significant CNS-related adverse events (AEs). ${ }^{[18]}$ Therefore, there still remains an unmet clinical need for a potent, safe, and peripherally selective $\mathrm{D} \beta \mathrm{H}$ inhibitor.

Etamicastat [BIA 5-453; (R)-5-(2-aminoethyl)-1(6,8-difluorochroman-3-yl)-1,3-dihydroimidazole-2thione hydrochloride] (figure 1) is intended to act as a reversible inhibitor of peripheral $\mathrm{D} \beta \mathrm{H}$ with limited access to the brain. ${ }^{[17]}$ Following oral administration of etamicastat, a blood pressurelowering effect was observed in studies performed with spontaneously hypertensive rats (SHR). Both the systolic and diastolic blood pressure (but not the heart rate) were decreased in SHR rats in a dose-dependent manner, an effect not observed in normotensive control rats. ${ }^{[19]}$ Chronically administered etamicastat in drinking water also significantly reduced both blood pressure and norepinephrine urinary excretion in SHR rats. In parallel, the urinary excretion of dopamine increased significantly but only in SHR rats. ${ }^{[20]}$

Etamicastat safety, tolerability, and pharmacokinetics were investigated in a previous entryinto-man single-dose, double-blind, randomized, placebo-controlled study in healthy subjects in
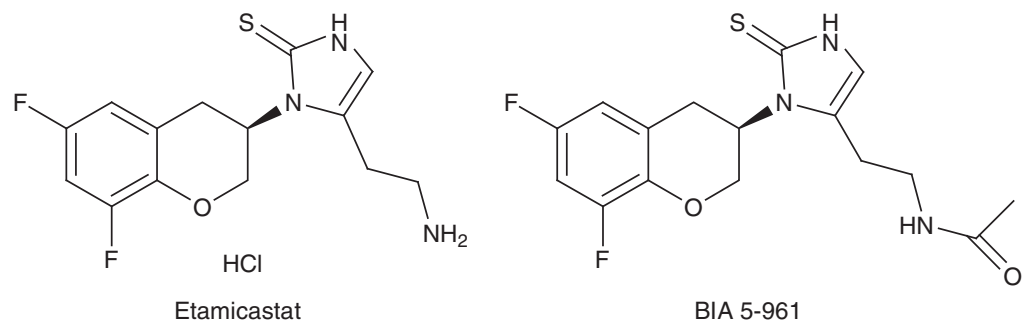

Fig. 1. Structural formulae of etamicastat (BIA 5-453) and its acetylated metabolite BIA 5-961. 
the dose range $2-1200 \mathrm{mg} .{ }^{[21]}$ Maximum plasma concentrations $\left(\mathrm{C}_{\max }\right)$ occurred at $1-3$ hours after dosing. Elimination was bi-compartmental, characterized by a first short early elimination half-life $\left(t_{1 / 2}\right)$ followed by a longer $t_{1 / 2}$ of $16-20$ hours for etamicastat doses $\geq 100 \mathrm{mg}$. In a food interaction study in healthy subjects, the absorption of etamicastat was delayed by the presence of food, but no significant effect was observed in the extent of systemic exposure to etamicastat, as assessed by the area under the plasma concentration-time curve (AUC). ${ }^{[22]}$

$\mathrm{N}$-Acetyltransferase (NAT) is one of the major hepatic phase II enzymes involved in drug metabolism. Humans express two functional NAT isoforms: NAT1 and NAT2. ${ }^{[23]}$ Data from a previous single-dose study showed that $\mathrm{N}$-acetylation by NAT2 appeared to be the main metabolic pathway of etamicastat. ${ }^{[21]}$ Plasma exposure to the N-acetylated metabolite (BIA 5-961), which was shown to be inactive in in vitro and in vivo preclinical experiments (e.g. following intraperitoneal administration in mice and rats [BIAL unpublished observation]), increased in a dose proportional manner.

A high interindividual variability of pharmacokinetic parameters of etamicastat and BIA 5-961 was observed following single doses of etamicastat in healthy subjects. ${ }^{[21]}$ Pharmacogenomic data showed that such variability is mainly dependent upon the NAT2 phenotype (rapid or slow acetylating ability). ${ }^{[21]}$ Etamicastat was well tolerated at all the investigated dose levels. In the present work, we describe the results of a study aiming to evaluate the safety, tolerability, and pharmacokinetics of multiple-dose regimens of etamicastat in young healthy male volunteers.

\section{Population and Methods}

\section{Study Design and Ethics Compliance}

This was a phase I, double-blind, randomized, placebo-controlled, multiple-dose study investigating etamicastat oral doses of 25, 50, 100, 200, 400, and $600 \mathrm{mg}$ administered once-daily for 10 days to sequential groups of young healthy male subjects. The study was conducted according to the principles of the Declaration of Helsinki and the Good Clinical Practice (ICH) guidelines. An Independent Ethics Committee (Comite de Protection des Personnes [CCP] Ouest VI, Brest, France) reviewed and approved the study protocol and the subject information. Written informed consent was obtained for each subject prior to enrolment in the study. Subjects were required to sign a specific pharmacogenetic informed consent form to allow NAT1 and NAT2 genotyping and phenotyping.

\section{Participants}

Healthy male volunteers aged 18-45 years were eligible for this study. Health status was confirmed by medical history, physical examination and vital signs, electrocardiogram (ECG), and laboratory workup, including hematology, plasma biochemistry, urinalysis, and hepatitis B, hepatitis C, and HIV serology performed at screening.

Volunteers were excluded from participation if they (i) had any clinically relevant disorder; (ii) smoked more than 10 cigarettes per day; (iii) had a history of drug abuse or alcoholism within 1 year prior to admission; (iv) had an ECG corrected QT (QTc) interval reading at screening or enrolment $>450 \mathrm{~ms}$; (v) had positive serologic results for HIV antibodies, hepatitis B surface antigen, and/or hepatitis $\mathrm{C}$ virus antibodies; (vi) had positive results of urine drug screen (amphetamines, barbiturates, benzodiazepines, cannabinoids, cocaine, methadone, opiates, 3,4-methylenedioxymethamphetamine [ecstasy]) at screening and admission; (vii) had used any investigational drug within 90 days or prescription drug within 30 days prior to admission; (viii) had consumed any caffeine-containing products (e.g. coffee, tea, chocolate, or soda) in excess of six cups per day (or equivalent), grapefruit, grapefruit-containing products, or alcoholic beverages within 72 hours prior to admission; or (ix) had used any over-thecounter drugs including herbal supplements (except for the occasional use of acetaminophen [paracetamol], acetylsalicylic acid [aspirin] and vitamins within the recommended daily allowance) within 7 days prior to admission. No concomitant 
medication was allowed during the study unless required to treat an $\mathrm{AE}$.

\section{Interventions}

Participants underwent health status screening within 28 days before admission to the study. Following confirmation of eligibility, within each group of eight volunteers, two subjects were randomized to receive placebo and the remaining six subjects to receive etamicastat. Etamicastat doses of 25, 50, 100, 200, 400, and $600 \mathrm{mg}$ were investigated in ascending order and the decision to proceed to the next higher dose was made on the basis of tolerability assessments of the previous dose level. Due to the occurrence of a maculopapular rash of probable infectious origin in three of eight subjects in group 4 (placebo/etamicastat $200 \mathrm{mg}$ ), this group was repeated to rule out drug hypersensitivity before escalating to the next dose level.

Subjects were admitted to the research facility from day -2 (2 days before the first dose of investigational product) until approximately 72 hours after the last dosing. Subjects were then discharged from the research facility and instructed to return for a follow-up visit 4-7 days later. At admission, medical history, physical examination, and laboratory safety tests were updated. Supine and standing blood pressure and heart rate measurements and computerized 12-lead ECG recordings were obtained at frequent intervals during admission. Clinical laboratory tests were repeated on days 4 and 10, and 72 hours after the last dose (discharge). At the follow-up visit, the medical history was updated and clinical laboratory safety tests performed.

Etamicastat was administered once daily, in the morning (between 7:30am and 9:00am), for 10 days (days 1-10). Capsules of etamicastat or placebo identical in appearance were used. The doses of investigational product were administered with $250 \mathrm{~mL}$ of water following an overnight fasting of at least 8 hours. Subjects remained fasted for at least 4 hours post-dose on day 1 and day 10, and for at least 2 hours post-dose on the remaining treatment days.

A diet low in monoamines was adopted. The following food was not permitted from 3 days prior first dosing through 72 hours after last dosing:

- drinks - chocolate, cocoa, beer, alcohol, orange juice;

- fruits - banana, pineapple, orange, grapefruit, grapes, strawberries;

- dry fruits/nuts - almonds, peanuts, pistachios, prunes;

- vegetables - tomatoes, eggplants, broad beans;

- meat and fish - smoked fish, liver, brains; and

- cheese and vanilla-flavored desserts.

A normal sodium diet $(\mathrm{NaCl} 7 \mathrm{~g}$ /day) was provided.

\section{Safety Assessments}

Safety assessments consisted of AE monitoring, physical examinations, vital signs measurements, digital 12-lead ECG recordings, and clinical laboratory tests. During admission, blood pressure and heart rate measurements using a Dinamap $^{\circledR}$ (GE Healthcare, Chalfont St. Giles, UK) blood pressure monitor using the oscillometric method and 12-lead digital ECG recordings were taken in the supine position, after resting for at least 10 minutes, at the following times: (i) day -1 (the day prior to first dosing) time 0 (24 hours before first dosing) and 1, 2, 3, 4, $6,8,10,12$, and 16 hours after; (ii) day 1 (day of first dosing) - pre-dose and 1, 2, 3, 4, 6, 8, 10, 12, and 16 hours post-dose; (iii) from day 2 to day $9-$ pre-dose and 2 hours post-dose; and (iv) day 10 (day of last dosing) - pre-dose and 1, 2, 3, 4, 6, 8, $10,12,16,24,48$, and 72 hours post-dose. Digital ECGs were performed in triplicate (with an interval of 5 minutes, with a difference of at least 1 minute between each of the three recordings). The investigator was responsible for providing the interpretation of all ECGs. The results included heart rate, PR interval, QRS interval, QT interval, and QTc interval, with comments on normality or abnormality. Two corrections of the QT interval were investigated: Fridericia's correction $(\mathrm{QTcF})$ and Bazett's correction $(\mathrm{QTcB})$. The primary method of correction was QTcF. A manual reading of the digital ECGs was conducted to assess prolongation of QT/QTc intervals. 
All clinical AEs were monitored throughout the entire study period. Their severity (intensity) was categorized according a three-point scale (mild, moderate, and severe), and the causality (potential relationship to drug) was assessed by the investigator before breaking the blinding.

\section{Pharmacokinetic Assessments and} Bioanalytical Methods

Blood samples $(3 \mathrm{~mL})$ for determination of plasma concentrations of etamicastat and its metabolites were taken, by direct venepuncture or an intravenous catheter, into lithium-heparin tubes at the following times on days 1 and 10 : pre-dose, then at $0.5,1,2,3,4,5,6,8,10,12$, and 16 hours post-dose. Further blood samples were taken at 24, 36, 48, and 72 hours post-last dose. Pre-dose blood samples were also taken on days 2-9. After collection, blood samples were centrifuged at approximately $1500 \mathrm{~g}$ for 10 minutes at $4^{\circ} \mathrm{C}$. The resulting plasma was then separated into four aliquots of $250 \mu \mathrm{L}$ and stored at $-80^{\circ} \mathrm{C}$ until required for analysis. Urine samples for pharmacokinetic assessments were collected at pre-dose and over the intervals $0-4,4-8,8-12$, and 12-24 hours post-dose on day 1 , and at predose and over the intervals $0-4,4-8,8-12,12-24$, 24-36, 36-48, 48-60, and 60-72 hours after the last dose (day 10). Four aliquots of $500 \mu \mathrm{L}$ were prepared and stored at $-80^{\circ} \mathrm{C}$ until required for analysis.

For the preparation of calibration samples, etamicastat and BIA 5-961 were dissolved in methanol to a final concentration of $250 \mu \mathrm{g} / \mathrm{mL}$ (method in plasma) or $1250 \mu \mathrm{g} / \mathrm{mL}$ (method in urine). For the preparation of quality control (QC) samples, a second set of stock solutions was prepared. For calibration and QC samples, working solutions in methanol were added to plasma using a ratio of 2/98 (v/v). For the preparation of the internal standard (ISTD) solution, reference standard (BIA 5-1058; molecular formula $\mathrm{C}_{21} \mathrm{H}_{21} \mathrm{~F}_{2} \mathrm{~N}_{3} \mathrm{OS}$ ) was dissolved in methanol to a concentration of $1000 \mu \mathrm{g} / \mathrm{mL}$. Further dilutions to a final concentration of $555 \mathrm{ng} / \mathrm{mL}$ were done using methanol.

Plasma samples were vortexed and centrifuged for 20 minutes at approximately $3362 \mathrm{~g}$ after un- assisted thawing at room temperature. The method involved the addition of $300 \mu \mathrm{L}$ of acetonitrile/ ethanol $(50 / 50, \mathrm{v} / \mathrm{v})$ containing $555 \mathrm{ng} / \mathrm{mL}$ of ISTD and $300 \mu \mathrm{L}$ of acetonitrile to $100 \mu \mathrm{L}$ of plasma. After protein precipitation at room temperature, samples were centrifuged for 20 minutes at approximately $2773 \mathrm{~g}$ and $8^{\circ} \mathrm{C}$. The supernatant was transferred into a deep well plate. An aliquot of $10 \mu \mathrm{L}$ of the supernatant was injected onto the liquid chromatography coupled to mass spectrometric detection (LC-MS/MS) system. The analysis was done by separation with an injection volume of $10 \mu \mathrm{L}(10 \mu \mathrm{L}$ in a $10 \mu \mathrm{L}$ sample pool $)$ in reversed phase chromatography (column temperature $50^{\circ} \mathrm{C}$ ) followed by mass detection spectrometry.

Urine samples were vortexed and centrifuged for 20 minutes at approximately $3362 \mathrm{~g}$ after unassisted thawing at room temperature. To an aliquot of $20 \mu \mathrm{L}$ urine, $80 \mu \mathrm{L}$ lithium-heparin plasma was added and precipitated by $300 \mu \mathrm{L}$ of ISTD solution. After protein precipitation and short mixing at room temperature, samples were centrifuged for 20 minutes at approximately $2773 \mathrm{~g}$ and $8^{\circ} \mathrm{C}$. The supernatant $(250 \mu \mathrm{L})$ was transferred into an ultrafiltration filter plate and centrifuged for about 2 hours at approximately $2773 \mathrm{~g}$ and $20^{\circ} \mathrm{C}$. An aliquot of $5 \mu \mathrm{L}$ of the supernatant was injected onto the LC-MS/MS system. The analysis was done by separation with an injection volume of $5 \mu \mathrm{L}(5 \mu \mathrm{L}$ in a $10 \mu \mathrm{L}$ sample pool) in reversed phase chromatography (column temperature $50^{\circ} \mathrm{C}$ ) followed by mass detection spectrometry.

Plasma and urine concentrations of etamicastat and its metabolite BIA 5-961 were determined using validated methods consisting of LC-MS/MS. The LC-MS/MS system consisted of a Rheos 2200 pump (Flux Instruments, Basel, Switzerland), a PAL autosampler (CTC Analytics AG, Zurich, Switzerland) and a TSQ Quantum triple-stage quadrupole mass spectrometer (Thermo Fisher Scientific, San Jose, CA, USA). Separation was achieved using a Luna C8 (2), $2.0 \times 5.0 \mathrm{~mm}, 5 \mu \mathrm{m}$ analytical column (Phenomenex, Torrance, CA, USA), a C8, $2.0 \times 5.0 \mathrm{~mm}$, $5 \mu \mathrm{m}$ precolumn filter (Phenomenex, Torrance, CA, USA), a Gecko 2000 column heater (CIL, Courbevoise, France) at $50^{\circ} \mathrm{C}$ and a mobile phase 
$(0.5 \mathrm{~mL} / \mathrm{min})$ consisting of water containing $1.0 \%$ formic acid (phase A) and acetonitrile containing $1.0 \%$ formic acid (phase B). The MS detector was operated in positive ion mode.

Calibration curves - over the nominal concentration ranges of $5-5000 \mathrm{ng} / \mathrm{mL}$ for plasma assay or $25-25000 \mathrm{ng} / \mathrm{mL}$ for urine assay - and a set of QC samples (triplicates over three concentration levels) were analyzed with each batch of study samples. The QC samples were used to monitor the performance of the assay. In plasma, the data for the QC samples showed that the overall imprecision of the method, measured by the coefficient of variation, was $\leq 6.0 \%$ for etamicastat and $\leq 6.9 \%$ for BIA 5-961. The overall accuracy (as the proportion of the determined value in relation to the true or nominal value) ranged from $93.5 \%$ to $98.0 \%$ for etamicastat, and $93.5 \%$ to $98.0 \%$ for BIA 5-961. In urine, the overall imprecision was $\leq 10.0 \%$ for etamicastat and $\leq 7.8 \%$ for BIA $5-961$, and the overall accuracy ranged from $99.5 \%$ to $99.7 \%$ for etamicastat and $97.2 \%$ to $100.8 \%$ for BIA 5-961. The lower limit of quantification of the assay (LLOQ) was $5 \mathrm{ng} / \mathrm{mL}$ in plasma and $25 \mathrm{ng} / \mathrm{mL}$ in urine. Etamicastat, BIA 5-961 and reference standard (BIA 5-1058) were supplied by BIAL (Laboratory of Chemistry, S. Mamede do Coronado, Portugal).

\section{Pharmacodynamic Assessments}

Urine for the assessment of urinary levels of norepinephrine, dopamine, epinephrine and homovanillic acid was collected on day 1 at pre-dose and $0-4,4-8,8-12$, and 12-24 hours post-dose, and on day 10 at pre-dose and $0-4,4-8,8-12$, $12-24,24-36,36-48,48-60$, and $60-72$ hours post-dose. After collection, $3 \mathrm{~mL}$ aliquots of acidified urine were prepared and stored at $-80^{\circ} \mathrm{C}$. The determination of urine levels of catecholamines was carried out by high performance LC with electrochemical detection using a validated method. The LC electrochemical detection system consisted of a pump (Gilson 302) and a stainless steel 5- $\mu \mathrm{m}$ ODS2 column (Biophase; Bioanalytical Systems, West Lafayette, IN, USA), measuring $250 \mathrm{~mm}$ in length and $4.6 \mathrm{~mm}$ in diameter; samples were injected by means of an automatic sample injector (Triathlon-Spark Holland, Emmen, the Netherlands). The mobile phase was a degassed solution consisting of citric acid $(0.1 \mathrm{mmol} / \mathrm{L})$, sodium octylsulfate $(0.5 \mathrm{mmol} / \mathrm{L})$, sodium acetate $(0.1 \mathrm{~mol} / \mathrm{L})$, Na2EDTA $(0.17 \mathrm{mmol} / \mathrm{L})$, dibutylamine $(1 \mathrm{mmol} / \mathrm{L})$, and methanol $(10 \%$ $\mathrm{v} / \mathrm{v})$, adjusted to $\mathrm{pH} 3.5$ with perchloric acid $(2 \mathrm{~mol} / \mathrm{L})$, and pumped at a rate of $1.0 \mathrm{~mL} / \mathrm{min}$. The detection was carried out electrochemically with a glassy carbon electrode, an $\mathrm{Ag} / \mathrm{AgCl}$ reference electrode, and an amperometric detector (Intro-Antec Leyden for norepinephrine, dopamine, epinephrine, and Gilson 141 for homovanillic acid); the detector cell was operated at $0.75 \mathrm{~V}$. The lower limits of detection of norepinephrine, dopamine, epinephrine, and homovanillic acid were 22, 19, 37, and $500 \mathrm{ng} / \mathrm{L}$, respectively.

\section{Determination of Subjects NAT1 and NAT2 Genotypes}

The NAT1 and NAT2 genes were genotyped for all subjects participating in the current study. Genomic DNA was extracted from total venous blood. For NAT1, eight single nucleotide polymorphisms (SNPs) were analyzed $(190 \mathrm{C}>\mathrm{T}, 445$ $\mathrm{G}>\mathrm{A}, 459 \mathrm{G}>\mathrm{A}, 559 \mathrm{C}>\mathrm{T}, 560 \mathrm{G}>\mathrm{A}, 640 \mathrm{~T}>\mathrm{G}$, $1088 \mathrm{~T}>\mathrm{A}$, and $1095 \mathrm{C}>\mathrm{A}$ ) and the corresponding genotypes determined. Associated genotypes were defined according to the literature. ${ }^{[17,24]}$ Subjects were classified NAT1 rapid (fast) acetylators if they carried the NAT $1 * 10$ (except NAT $1 * 10 /{ }^{*} 14$ ) or NAT1*11 alleles, normal acetylators if they carried the NAT1*4 or NAT1*3 alleles or the NAT $1 * 10 / * 14$ genotype, and poor (slow) acetylators if they carried the NAT1*14 (except NAT1*10/14) or NAT1*17 alleles. For NAT2, four coding SNPs were analyzed (191 G > A, 341 $\mathrm{T}>\mathrm{C}, 590 \mathrm{G}>\mathrm{A}$, and $857 \mathrm{G}>\mathrm{A}$ ) and the corresponding genotypes determined. Associated genotypes were defined according to the literature. ${ }^{[25,26]}$ The NAT2* 4 allele encodes for a fully active enzyme and is considered the wild type (rapid acetylator) allele. Subjects were classified NAT2 rapid acetylators if they carried the NAT $2 * 4 /{ }^{*} 4$ allele or the NAT $2 * 4 / * 5, \mathrm{NAT} 2 * 4 / * 6$ or NAT $2 * 4 * 7$ genotype, and poor acetylators if they carried the NAT $2 * 5 / * 5$, NAT $2 * 6 / * 6$ or NAT $2 * 7 / * 7$ alleles, 
Table I. Main demographic details by treatment dose group

\begin{tabular}{|c|c|c|c|c|c|c|c|}
\hline \multirow[t]{2}{*}{ Parameter } & \multirow{2}{*}{$\begin{array}{l}\text { Placebo } \\
(n=15)\end{array}$} & \multicolumn{6}{|c|}{ Etamicastat dose group } \\
\hline & & $\begin{array}{l}25 \mathrm{mg} \\
(\mathrm{n}=6)\end{array}$ & $\begin{array}{l}50 \mathrm{mg} \\
(\mathrm{n}=6)\end{array}$ & $\begin{array}{l}100 \mathrm{mg} \\
(n=6)\end{array}$ & $\begin{array}{l}200 \mathrm{mg} \\
(\mathrm{n}=12)\end{array}$ & $\begin{array}{l}400 \mathrm{mg} \\
(\mathrm{n}=6)\end{array}$ & $\begin{array}{l}600 \mathrm{mg} \\
(\mathrm{n}=6)\end{array}$ \\
\hline $\begin{array}{l}\text { Mean age } \pm S D \\
\text { [y] (range) }\end{array}$ & $\begin{array}{l}30.6 \pm 6.4 \\
(18-40)\end{array}$ & $\begin{array}{l}26.5 \pm 6.7 \\
(21-39)\end{array}$ & $\begin{array}{l}36.0 \pm 4.5 \\
(31-43)\end{array}$ & $\begin{array}{l}31.5 \pm 4.9 \\
(27-39)\end{array}$ & $\begin{array}{l}31.3 \pm 7.9 \\
(20-45)\end{array}$ & $\begin{array}{l}31.0 \pm 8.7 \\
(22-44)\end{array}$ & $\begin{array}{l}28.8 \pm 6.5 \\
(23-40)\end{array}$ \\
\hline $\begin{array}{l}\text { Mean height } \pm S D \\
{[\mathrm{~cm}] \text { (range) }}\end{array}$ & $\begin{array}{l}175.8 \pm 8.0 \\
(158-186)\end{array}$ & $\begin{array}{l}175.7 \pm 3.3 \\
(173-182)\end{array}$ & $\begin{array}{l}175.2 \pm 5.2 \\
(170-183)\end{array}$ & $\begin{array}{l}176.8 \pm 9.3 \\
(168-191)\end{array}$ & $\begin{array}{l}177.8 \pm 6.9 \\
(170-193)\end{array}$ & $\begin{array}{l}177.3 \pm 6.7 \\
(168-187)\end{array}$ & $\begin{array}{l}177.2 \pm 5.6 \\
(167-183)\end{array}$ \\
\hline $\begin{array}{l}\text { Mean } \mathrm{BMI} \pm \mathrm{SD} \\
{\left[\mathrm{kg} / \mathrm{m}^{2}\right] \text { (range) }}\end{array}$ & $\begin{array}{l}22.5 \pm 2.9 \\
(19.0-29.4)\end{array}$ & $\begin{array}{l}23.0 \pm 2.8 \\
(19.4-26.4)\end{array}$ & $\begin{array}{l}23.1 \pm 1.3 \\
(20.8-24.7)\end{array}$ & $\begin{array}{l}22.5 \pm 2.1 \\
(20.3-25.7)\end{array}$ & $\begin{array}{l}24.7 \pm 2.8 \\
(20.0-28.4)\end{array}$ & $\begin{array}{l}23.9 \pm 1.5 \\
(22.0-26.1)\end{array}$ & $\begin{array}{l}22.3 \pm 2.4 \\
(19.4-25.5)\end{array}$ \\
\hline \multicolumn{8}{|l|}{ Race [n (\%)] } \\
\hline Caucasian & $13(86.7)$ & $6(100)$ & 5 (83.3) & $4(66.7)$ & $6(50)$ & 5 (83.3) & $6(100)$ \\
\hline other & $2(13.3)$ & 0 & $1(16.7)$ & 2 (33.3) & $6(50)$ & $1(16.7)$ & 0 \\
\hline
\end{tabular}

or the NAT $2 * 5 / * 6, \mathrm{NAT} 2 * 5 / * 7$ or NAT $2 * 6 / 7$ genotype.

\section{Analyses}

For this exploratory study, no formal sample size calculation was performed. Eight subjects per treatment (six subjects assigned to active treat- ment and two subjects assigned to placebo) are a standard number of subjects per treatment group in early clinical trials in healthy subjects and were considered compatible with a reasonable clinical interpretation and descriptive statistics.

AEs were tabulated and summarized according to the Medical Dictionary for Regulatory Activities (MedDRA). Blood pressure, heart rate,

Table II. Number (\%) of subjects reporting any treatment-emergent adverse event

\begin{tabular}{|c|c|c|c|c|c|c|c|}
\hline \multirow[t]{2}{*}{ MedDRA preferred term } & \multirow{2}{*}{$\begin{array}{l}\text { Placebo } \\
(n=15)\end{array}$} & \multicolumn{6}{|c|}{ Etamicastat dose group } \\
\hline & & $\begin{array}{l}25 \mathrm{mg} \\
(\mathrm{n}=6)\end{array}$ & $\begin{array}{l}50 \mathrm{mg} \\
(\mathrm{n}=6)\end{array}$ & $\begin{array}{l}100 \mathrm{mg} \\
(\mathrm{n}=6)\end{array}$ & $\begin{array}{l}200 \mathrm{mg} \\
(\mathrm{n}=12)\end{array}$ & $\begin{array}{l}400 \mathrm{mg} \\
(\mathrm{n}=6)\end{array}$ & $\begin{array}{l}600 \mathrm{mg} \\
(\mathrm{n}=6)\end{array}$ \\
\hline Conjunctivitis & $1(6.7)$ & & & & & & \\
\hline Diarrhea & & & & & & & $5(83.3)$ \\
\hline Flatulence & $1(6.7)$ & & & & & & $1(16.7)$ \\
\hline Nausea & & & & & $1(8.3)$ & & $1(16.7)$ \\
\hline Vomiting & & & & & $1(8.3)$ & & \\
\hline Pyrexia & & & & & $1(8.3)$ & & \\
\hline Ear infection & & & & & $1(8.3)$ & & \\
\hline Nasopharyngitis & & $1(16.7)$ & & $1(16.7)$ & & & \\
\hline Rhinitis & $1(6.7)$ & $1(16.7)$ & & $2(33.3)$ & & & \\
\hline Pain in extremity & & & & & $1(8.3)$ & & \\
\hline Dizziness & & & & $1(16.7)$ & & & \\
\hline Headache & $1(6.7)$ & & & & $3(25.0)$ & $1(16.7)$ & \\
\hline Syncope, vasovagal & & & & & $1(8.3)$ & & \\
\hline Pruritus & & & & & $1(8.3)$ & & \\
\hline Rash papular & & & & & $3(25.0)$ & & \\
\hline Urticaria & & & & & & & $1(16.7)$ \\
\hline Total $^{\mathrm{a}}$ & $3(20.0)$ & $2(33.3)$ & 0 & $4(66.7)$ & $5(41.7)$ & $1(16.7)$ & $6(100)$ \\
\hline
\end{tabular}


vital signs, and clinical laboratory data were summarized using descriptive statistics. For the laboratory safety data, out-of-range values were flagged in the data listings and a list of abnormal values was presented. Any clinically significant abnormality was considered as an AE.

The following parameters were calculated for supine systolic (SBP) and diastolic (DBP) blood pressure, ECG-measured heart rate and QTcF: maximum observed effect $\left(\mathrm{E}_{\max }\right)$, time to $\mathrm{E}_{\max }$ $\left(t_{E \operatorname{Emax}}\right)$ and area under the effect-time curve over 24 hours $\left(\mathrm{AUC}_{\mathrm{EC}}\right)$. The parameters were summarized using descriptive statistics. $\mathrm{E}_{\max }$ and $\triangle \mathrm{AUC}_{\mathrm{EC}}$ (difference in $\mathrm{AUC}_{\mathrm{EC}}$ in relation to $\mathrm{AUC}_{\mathrm{EC}}$ on day -1) were compared at day 1 and day 10 between dose groups by using a one-way analysis of variance with dose group as the fixed effect. If global treatment effect was significant, a multiple-comparisons Dunnett's test was performed to compare each dose group versus placebo. $\mathrm{E}_{\max }$ at day 10 was tested versus $\mathrm{E}_{\max }$ at day 1 using a paired Student's t-test in each dose group.

The following pharmacokinetic parameters for etamicastat and its metabolites were derived by non-compartmental analysis from the individual plasma concentration-time profiles: time of occurrence of $\mathrm{C}_{\max }\left(\mathrm{t}_{\max }\right)$; AUC from time zero to the last sampling time at which concentrations were at or above the limit of quantification $\left(\mathrm{AUC}_{\mathrm{t}}\right)$ and $\mathrm{AUC}$ over 24 hours $\left(\mathrm{AUC}_{24}\right)$, both calculated by the trapezoidal rule, and AUC from time zero to infinity $\left(\mathrm{AUC}_{\infty}\right)$, calculated from $\mathrm{AUC}_{\mathrm{t}}+\left(\mathrm{C}_{\text {last }} / \lambda_{\mathrm{z}}\right)$, where $\mathrm{C}_{\text {last }}$ is the last quantifiable concentration; the apparent terminal rate constant $\left(\lambda_{z}\right)$ and corresponding terminal $t_{1 / 2}$ calculated from $\ln 2 / \lambda_{7}$; observed accumulation ratio $\left(\mathrm{R}_{\mathrm{O}}\right)$, calculated from $\mathrm{AUC}_{24}$ (day 10)/AUC $\mathrm{AU}_{24}$ (day 1); and theoretical accumulation ratio $\left(\mathrm{R}_{\mathrm{T}}\right)$, calculated from $1 /\left(1-\mathrm{e}^{-\lambda_{z} \bullet \tau}\right)$, where $\tau$ is the dosing interval. The volume of distribution $(\mathrm{V} / \mathrm{F})$ and the renal clearance of drug from plasma $\left(\mathrm{CL}_{\mathrm{R}}\right)$, calculated from $\mathrm{Ae} / \mathrm{AUC}_{\infty}$, where Ae is the cumulative amount of drug excreted in the urine, were also derived. Nominal sampling times were used for the pharmacokinetic analysis. Plasma concentrations below the limit of quantification of the assay were taken as zero for all calculations. All calculations were made using raw data.
Summary statistics of all data were reported, as appropriate, using the geometric mean, arithmetic mean, standard deviation (SD), coefficient of variation $(\mathrm{CV} \%)$, standard error of the mean (SEM), median, and range (minimum and maximum). A nonlinear power model was used to assess dose proportionality of $\mathrm{C}_{\max }$ and $\mathrm{AUC}_{24}$. The relationship is written as a power function: parameter $=a \bullet \operatorname{dose}^{b}$, where $a$ is a constant, $b$ is the proportionality constant, and parameter is $\mathrm{C}_{\max }$ or $\mathrm{AUC}_{24}$. Linearization of this relationship gives: $\log$ parameter $=\log a+\log \operatorname{dose} \bullet b$. The relationship is dose proportional when $b=1$. The exponent of the power function, with $95 \%$ confidence intervals $(95 \% \mathrm{CI})$, was fitted to the in-

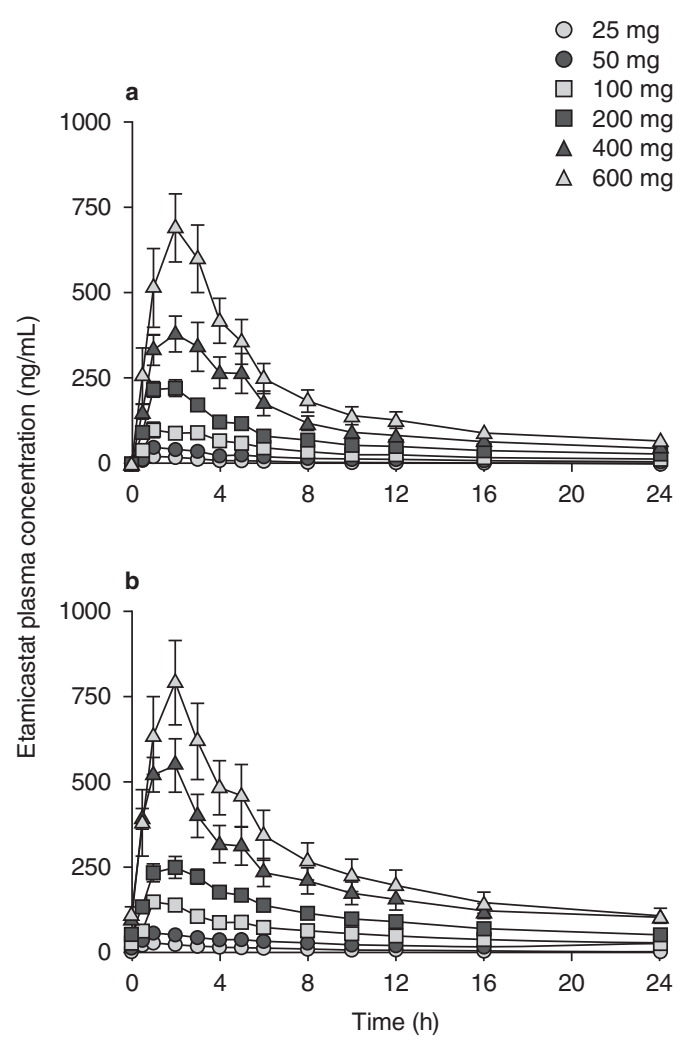

Fig. 2. Plasma concentration (mean $\pm S E M)$ vs time profiles of etamicastat following single (day 1 [a]) and repeated (day 10 [b]) oral once-daily administration of etamicastat in the dose range 25-600 mg (etamicastat $200 \mathrm{mg}: \mathrm{n}=12$; other dose groups: $n=6$ per dose group). 
Table III. Pharmacokinetic parameters of etamicastat following the first dose (day 1) and the final dose (day 10) of repeated administration of etamicastat to healthy subjects ${ }^{a}$

\begin{tabular}{|c|c|c|c|c|c|c|c|}
\hline \multirow[t]{2}{*}{ Parameter } & \multirow[t]{2}{*}{ Dose } & \multicolumn{6}{|c|}{ Etamicastat dose group } \\
\hline & & $25 \mathrm{mg}(\mathrm{n}=6)$ & $50 \mathrm{mg}(\mathrm{n}=6)$ & $100 \mathrm{mg}(\mathrm{n}=6)$ & $200 \mathrm{mg}(\mathrm{n}=12)$ & $400 \mathrm{mg}(\mathrm{n}=6)$ & $600 \mathrm{mg}(\mathrm{n}=6)$ \\
\hline \multirow[t]{2}{*}{$\overline{C_{\max }(n g / m L)}$} & First & $23 \pm 7$ & $56 \pm 17$ & $128 \pm 40$ & $251 \pm 72$ & $468 \pm 99$ & $722 \pm 265$ \\
\hline & Last & $32 \pm 12$ & $65 \pm 28$ & $153 \pm 40$ & $275 \pm 87$ & $596 \pm 154$ & $866 \pm 280$ \\
\hline \multirow[t]{2}{*}{$t_{\max }(h)$} & First & $1.5(0.5-2.0)$ & $1.0(1.0-3.0)$ & $1.5(1.0-3.0)$ & $1.5(1.0-4.0)$ & $3.0(1.0-5.0)$ & $2.0(1.0-3.0)$ \\
\hline & Last & $1.0(0.5-2.0)$ & $1.0(1.0-2.0)$ & $1.0(1.0-2.0)$ & $2.0(1.0-3.0)$ & $2.0(1.0-2.0)$ & $2.0(1.0-2.0)$ \\
\hline \multirow[t]{2}{*}{$\mathrm{AUC}_{\mathrm{t}}(\mathrm{ng} \bullet \mathrm{h} / \mathrm{mL})$} & First & $147 \pm 108$ & $399 \pm 157$ & $862 \pm 283$ & $1746 \pm 521$ & $3095 \pm 1056$ & $4804 \pm 1829$ \\
\hline & Last & $397 \pm 394$ & $1018 \pm 719$ & $2302 \pm 867$ & $4125 \pm 1437$ & $7466 \pm 2865$ & $9126 \pm 4195$ \\
\hline \multirow[t]{2}{*}{$\mathrm{AUC}_{24}(\mathrm{ng} \bullet \mathrm{h} / \mathrm{mL})$} & First & $165 \pm 99$ & $405 \pm 150$ & $863 \pm 284$ & $1748 \pm 522$ & $3097 \pm 1057$ & $4806 \pm 1830$ \\
\hline & Last & $307 \pm 183$ & $664 \pm 328$ & $1460 \pm 4733$ & $2662 \pm 886$ & $4957 \pm 1860$ & $6484 \pm 2848$ \\
\hline $\mathrm{AUC}_{\infty}(\mathrm{ng} \bullet \mathrm{h} / \mathrm{mL})$ & Last & $562 \pm 491$ & $1334 \pm 776$ & $2740 \pm 1168$ & $4601 \pm 1597$ & $8094 \pm 3145$ & $9826 \pm 4605$ \\
\hline \multirow[t]{2}{*}{$t_{1 / 2}(h)$} & First & $8.7 \pm 7.6$ & $13.7 \pm 3.2$ & $13.0 \pm 3.0$ & $14.7 \pm 1.9$ & $13.7 \pm 2.1$ & $13.0 \pm 3.3$ \\
\hline & Last & $18.1 \pm 11.6$ & $25.6 \pm 6.2$ & $25.7 \pm 3.6$ & $22.2 \pm 2.9$ & $20.3 \pm 2.6$ & $20.3 \pm 1.6$ \\
\hline $\mathrm{R}_{\mathrm{T}}$ & Last & $1.7 \pm 0.7$ & $2.1 \pm 0.4$ & $2.1 \pm 0.2$ & $1.9 \pm 0.2$ & $1.8 \pm 0.1$ & $1.8 \pm 0.1$ \\
\hline $\mathrm{R}_{\mathrm{O}}$ & Last & $1.9 \pm 0.3$ & $1.6 \pm 0.3$ & $1.7 \pm 0.1$ & $1.6 \pm 0.2$ & $1.6 \pm 0.1$ & $1.3 \pm 0.2$ \\
\hline $\mathrm{CL}_{\mathrm{R}}(\mathrm{L} / \mathrm{h})$ & Last & $15.2 \pm 5.5$ & $11.9 \pm 1.9$ & $14.6 \pm 2.1$ & $16.0 \pm 3.1$ & $13.2 \pm 2.0$ & $15.2 \pm 1.7$ \\
\hline $\mathrm{V} / \mathrm{F}(\mathrm{L})$ & Last & $343 \pm 148$ & $440 \pm 125$ & $540 \pm 119$ & $517 \pm 135$ & $393 \pm 107$ & $445 \pm 40$ \\
\hline
\end{tabular}

a Data are given as mean $\pm S D$ (median and range for $t_{\text {max }}$ ).

$\mathbf{A} \mathbf{U C}_{\mathbf{2 4}}=$ area under the plasma concentration-time curve from time 0 to 24 hours; $\mathbf{A} \mathbf{U C}_{\mathbf{t}}=$ area under the plasma concentration-time curve from time zero to time t; $\mathbf{A} \mathbf{U C}_{\infty}=$ area under the plasma concentration-time curve from time zero to infinity; $\mathbf{C}_{\max }=$ maximum concentration; $\mathbf{C L}_{\mathbf{R}}=$ renal clearance; $\mathbf{R}_{\mathbf{O}}=$ observed accumulation ratio; $\mathbf{R}_{\mathbf{T}}=$ theoretical accumulation ratio; $\mathbf{t}_{1 / 2}=$ elimination half-life; $\mathbf{t}_{\mathbf{m a x}}=$ time to maximum concentration; $\mathbf{V} / \mathbf{F}=$ volume of distribution.

dividual $\mathrm{C}_{\max }$ and $\mathrm{AUC}_{24}$. For determination of time to steady-state of plasma concentrations, a pairwise comparison for pre-dose concentrations between day 2 and day 10 was performed by dose group using a paired Student's t-test. Values at each period and cumulated values of urinary catecholamines were summarized using descriptive statistics by dose group.

The pharmacokinetic parameters were calculated with WinNonlin (version 5.0.1, Pharsight Corporation, Mountain View, CA, USA). Statistical calculations were performed with SAS ${ }^{\circledR}$ Software (version 8.2, SAS Institute Inc., Cary, NC, USA). The $\alpha$ risk p-values reported are two-sided and the statistical significance nominal limit was set to 0.05 .

\section{Results}

\section{Study Population}

Of 94 participants screened, 37 were deemed ineligible because they met exclusion criteria or failed to show up at the start of the study. A total of 57 male volunteers, aged $18-45($ median $=30)$ years were enrolled in the study. The demographic characteristics of the study population by treatment group are summarized in table I. One subject administered placebo withdrew his consent and was replaced. No relevant differences in demographic characteristics were found between treatment groups.

\section{Safety Results}

During the course of the study, a total of 32 treatment-emergent AEs were reported by 21 subjects (table II). The most frequent treatmentemergent AE was diarrhea. There were no serious AEs. All AEs were mild to moderate in intensity. An outbreak of maculopapular rash occurred in three subjects administered etamicastat $200 \mathrm{mg}$. Subjects had elevated antistreptolysin $\mathrm{O}$ titers, and antibiotics were prescribed. In the three subjects, histamine, tryptase $\mathrm{C} 3, \mathrm{C} 4$, and $\mathrm{C} 1 \mathrm{q}$ were normal, there was no hypereosinophilia and 
there was a moderate increase of C-reactive protein. Although an infection appeared to be a plausible cause, drug hypersensitivity could not be ruled out. Thus, a decision was made to repeat the placebo/etamicastat $200 \mathrm{mg}$ group before escalating to the subsequent dose level (placebo/ etamicastat $400 \mathrm{mg}$ ).

Clinical laboratory evaluations indicated no clinically significant abnormality. There was no statistically significant change in QTcF. There was no evidence for prolongation of the QT interval. All QTcF values remained below the limit of 0.450 seconds. There were no apparent trends in ECG parameters over time, and there were no apparent differences between dose groups.

\section{Pharmacokinetic Results}

Due to the occurrence of rash, the tenth dose was skipped in two subjects administered etamicastat $200 \mathrm{mg}$, and the pharmacokinetic profiling planned for day 10 was performed after day 9 dosing. All other subjects of the pharmacokinetic population completed the treatment period as planned.

Mean etamicastat plasma concentration-time profiles following the first and last doses of etamicastat are displayed in figure 2 , and the corresponding pharmacokinetic parameters are presented in table III. As expected, etamicastat was shown to be metabolized to BIA 5-961. Plasma concentration-time profiles of BIA 5-961 are displayed in figure 3 , and the corresponding mean pharmacokinetic parameters are presented in table IV. Figure 4 displays the mean trough (pre-dose) plasma concentrations of etamicastat and BIA 5-961 during the treatment period.

Etamicastat $\mathrm{C}_{\max }$ was reached $1-3$ hours postdose and declined thereafter, with an approximate mean apparent $t_{1 / 2}$ of $9-15$ hours following the first dose of etamicastat and 18-26 hours following repeated administration. $\mathrm{C}_{\max }$ of BIA 5-961 was reached 2-4 hours post-dose and declined thereafter, with a mean $t_{1 / 2}$ of $4-8$ hours following the first dose of etamicastat and 7-23 hours following repeated administration. Systemic exposure to etamicastat and BIA 5-961 increased with increasing doses on both day 1 and

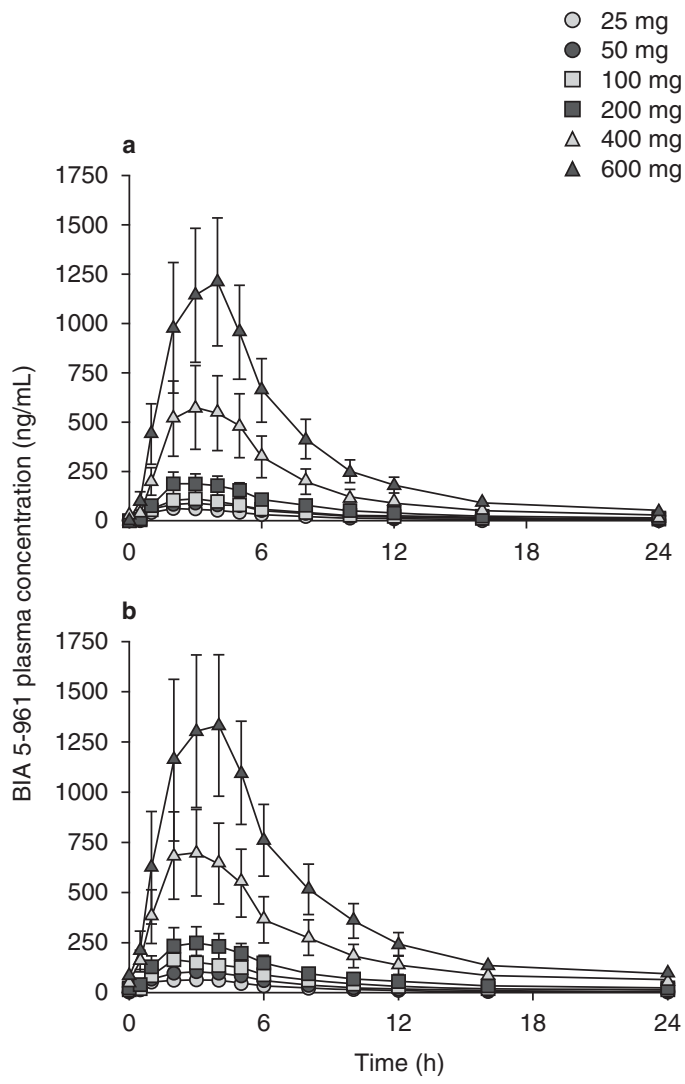

Fig. 3. Plasma concentration (mean $\pm S E M$ ) vs time profiles of BIA 5-961 following single (day 1 [a]) and repeated (day 10 [b]) oral oncedaily administration of etamicastat in the dose range $25-600 \mathrm{mg}$ (etamicastat $200 \mathrm{mg}: \mathrm{n}=12$; other dose groups: $n=6$ per dose group).

day 10 (table $\mathrm{V}$ and figure 5). The apparent doseproportional increase in systemic exposure was confirmed by the statistical analysis using an exponential regression model. Also, the comparison of etamicastat and BIA 5-961 pharmacokinetic parameters after log-transformation and dosenormalization showed that $\mathrm{C}_{\max }, \mathrm{AUC}_{\mathrm{t}}$ and $\mathrm{AUC}_{24}$ following the first dose of etamicastat, and $\mathrm{C}_{\max }, \mathrm{AUC}_{\mathrm{t}}, \mathrm{AUC}_{24}$, and $\mathrm{AUC}_{\infty}$ following the last dose were not significantly different between dose groups.

The $\mathrm{R}_{\mathrm{O}}$ indicating the extent to which etamicastat accumulated relative to the first dose ranged from 1.3 to 1.9. This ratio was lower than $\mathrm{R}_{\mathrm{T}}$, which ranged from 1.7 to 2.1 . This is in 
accordance with the apparent $t_{1 / 2}$ of $9-15$ hours following etamicastat first dose and 18-26 hours following etamicastat last dose. The $\mathrm{R}_{\mathrm{O}}$ for BIA 5-961 was also relatively low, ranging from 1.3 to 1.6 .

The one-way analysis of variance using trough (pre-dose) etamicastat plasma concentrations from day 2 to day 10 showed that steady state was reached at day $9(200 \mathrm{mg})$, day $8(400 \mathrm{mg})$ and before day 6 for the remaining dose groups. For BIA 5-961, steady state was reached at day 9 (200 and $600 \mathrm{mg})$, day $8(25 \mathrm{mg})$, and before day 6 for the remaining groups.

The cumulative amounts of etamicastat and BIA 5-961 recovered in urine are displayed in figure 6 . Urine drug recovery occurred predominantly over the first 12 hours after etamicastat administration. The excretion rate of etamicastat ranged from $0.3 \pm 0.1 \mathrm{mg} / \mathrm{h}(25 \mathrm{mg})$ to $8.5 \pm 3.2 \mathrm{mg} / \mathrm{h}$ $(600 \mathrm{mg})$ following the first dose and from $0.4 \pm 0.2 \mathrm{mg} / \mathrm{h}(25 \mathrm{mg})$ to $10.6 \pm 2.8 \mathrm{mg} / \mathrm{h}(600 \mathrm{mg})$ following the last dose. For BIA 5-961, the excretion rate ranged from $0.7 \pm 0.6 \mathrm{mg} / \mathrm{h}(25 \mathrm{mg})$ to
$10.4 \pm 6.9 \mathrm{mg} / \mathrm{h}(600 \mathrm{mg})$ and from $0.753 \pm 0.560$ $\mathrm{mg} / \mathrm{h}(25 \mathrm{mg})$ to $15.2 \pm 9.8 \mathrm{mg} / \mathrm{h}(600 \mathrm{mg})$, respectively. Renal clearance was relatively similar at the different dose levels, ranging from 11.9 to $16.0 \mathrm{~L} / \mathrm{h}$ for etamicastat and from 11.3 to $14.8 \mathrm{~L} / \mathrm{h}$ for BIA 5-961.

The interindividual variability in the pharmacokinetic parameters was high for both etamicastat and BIA 5-961, with mean CV close to $100 \%$ in some parameters. This variability is due to the different subjects' NAT2 phenotype (fast/slow acetylating ability), which affects the rate of biotransformation of etamicastat into BIA 5-961. Table VI presents the distribution of the different subjects' NAT1 and NAT2 phenotypes within each etamicastat dose group. No relevant effect of NAT1 phenotype on etamicastat pharmacokinetics was apparent. Etamicastat pharmacokinetics was shown to be markedly affected by the NAT2 status (figure 7). The extent of systemic exposure to etamicastat in NAT2 slow acetylators was 1.5-6.7 times higher than in NAT2 fast acetylators. BIA 5-961 exposure was

Table IV. Pharmacokinetic parameters of BIA 5-961 following the first dose (day 1) and the final dose (day 10) of repeated administration of etamicastat to healthy subjects ${ }^{a}$

\begin{tabular}{|c|c|c|c|c|c|c|c|}
\hline \multirow[t]{2}{*}{ Parameter } & \multirow[t]{2}{*}{ Dose } & \multicolumn{6}{|c|}{ Etamicastat dose group } \\
\hline & & $25 \mathrm{mg}(\mathrm{n}=6)$ & $50 \mathrm{mg}(\mathrm{n}=6)$ & $100 \mathrm{mg}(\mathrm{n}=6)$ & $200 \mathrm{mg}(\mathrm{n}=12)$ & $400 \mathrm{mg}(\mathrm{n}=6)$ & $600 \mathrm{mg}(\mathrm{n}=6)$ \\
\hline \multirow[t]{2}{*}{$\overline{\mathrm{C}_{\max }(\mathrm{ng} / \mathrm{mL})}$} & First & $65 \pm 55$ & $105 \pm 67$ & $119 \pm 47$ & $209 \pm 212$ & $625 \pm 516$ & $1286 \pm 865$ \\
\hline & Last & $66 \pm 45$ & $114 \pm 73$ & $166 \pm 103$ & $264 \pm 279$ & $731 \pm 545$ & $1420 \pm 989$ \\
\hline \multirow[t]{2}{*}{$t_{\max }(h)$} & First & $2.5(1.0-3.0)$ & $3.0(1.0-5.0)$ & $2.5(2.0-4.0)$ & $2.0(2.0-5.0)$ & $3.5(2.0-5.0)$ & $3.5(2.0-5.0)$ \\
\hline & Last & $3.0(2.0-4.0)$ & $2.5(2.0-4.0)$ & $2.0(2.0-4.0)$ & $4.0(2.0-5.0)$ & $2.5(2.0-3.0)$ & $3.5(2.0-4.0)$ \\
\hline \multirow[t]{2}{*}{$A \cup C_{t}(n g \bullet h / m L)$} & First & $403 \pm 352$ & $685 \pm 389$ & $838 \pm 328$ & $1518 \pm 1239$ & $4111 \pm 3311$ & $8291 \pm 5172$ \\
\hline & Last & $548 \pm 315$ & $924 \pm 461$ & $1634 \pm 768$ & $2699 \pm 2011$ & $7017 \pm 5313$ & $12203 \pm 7229$ \\
\hline \multirow[t]{2}{*}{$\mathrm{AUC}_{24}(\mathrm{ng} \bullet \mathrm{h} / \mathrm{mL})$} & First & $427 \pm 340$ & $694 \pm 377$ & $838 \pm 329$ & $1519 \pm 1240$ & $4113 \pm 3312$ & $8293 \pm 5173$ \\
\hline & Last & $513 \pm 327$ & $820 \pm 398$ & $1286 \pm 582$ & $2070 \pm 1707$ & $5603 \pm 4239$ & $10297 \pm 6560$ \\
\hline$A \cup C_{\infty}(\mathrm{ng} \bullet \mathrm{h} / \mathrm{mL})$ & Last & $615 \pm 355$ & $1069 \pm 524$ & $1853 \pm 905$ & $2926 \pm 2032$ & $7356 \pm 5477$ & $12516 \pm 7277$ \\
\hline \multirow{2}{*}{$t_{1 / 2}(h)$} & First & $3.9 \pm 1.1$ & $5.2 \pm 1.6$ & $6.4 \pm 0.8$ & $7.8 \pm 1.1$ & $7.5 \pm 1.0$ & $7.0 \pm 1.6$ \\
\hline & Last & $6.7 \pm 3.0$ & $15.8 \pm 7.1$ & $19.5 \pm 8.9$ & $22.5 \pm 4.4$ & $18.3 \pm 2.3$ & $17.0 \pm 2.5$ \\
\hline $\mathrm{R}_{\mathrm{T}}$ & Last & $1.1 \pm 0.1$ & $1.6 \pm 0.4$ & $1.8 \pm 0.5$ & $1.9 \pm 0.3$ & $1.77 \pm 0.1$ & $1.6 \pm 0.1$ \\
\hline $\mathrm{R}_{\mathrm{O}}$ & Last & $1.6 \pm 0.3$ & $1.3 \pm 0.5$ & $1.5 \pm 0.2$ & $1.3 \pm 0.2$ & $1.4 \pm 0.2$ & $1.3 \pm 0.1$ \\
\hline $\mathrm{CL}_{\mathrm{R}}(\mathrm{L} / \mathrm{h})$ & Last & $14.8 \pm 4.4$ & $11.6 \pm 1.1$ & $12.2 \pm 3.4$ & $12.7 \pm 3.3$ & $11.3 \pm 2.0$ & $13.6 \pm 1.8$ \\
\hline
\end{tabular}

a Data are given as mean $\pm S D$ (median and range for $t_{\text {max }}$ ).

$\mathbf{A} \mathbf{U C}_{\mathbf{2 4}}=$ area under the plasma concentration-time curve from time 0 to 24 hours; $\mathbf{A U C} \mathbf{C}_{\mathbf{t}}=$ area under the plasma concentration-time curve from time zero to time t; $\mathbf{A} \mathbf{U} \mathbf{C}_{\infty}=$ area under the plasma concentration-time curve from time zero to infinity; $\mathbf{C}_{\max }=$ maximum concentration; $\mathbf{C L}_{\mathbf{R}}=$ renal clearance; $\mathbf{R}_{\mathbf{O}}=$ observed accumulation ratio; $\mathbf{R}_{\mathbf{T}}=$ theoretical accumulation ratio; $\mathbf{t}_{1 / 2}=$ elimination half-life; $\mathbf{t}_{\text {max }}=$ time to maximum concentration. 


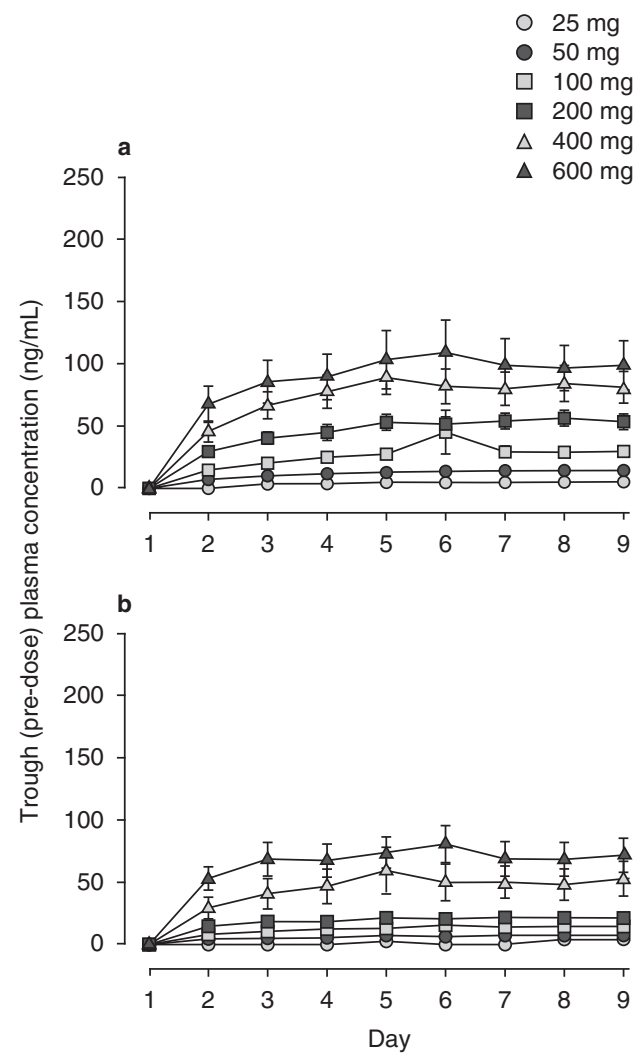

Fig. 4. Trough (pre-dose) plasma concentrations (mean \pm SEM) of (a) etamicastat and (b) BIA 5-961 during oral once-daily administration of etamicastat in the dose range $25-600 \mathrm{mg}$ (etamicastat $200 \mathrm{mg}: \mathrm{n}=12$; other dose groups: $\mathrm{n}=6$ per dose group).

1.5-3.5 times higher in rapid NAT2 acetylators. These results explain the high variability observed in the main etamicastat and BIA 5-961 pharmacokinetic parameters.

\section{Pharmacodynamic Results}

The cumulative amounts of norepinephrine recovered in urine over a 24 -hour interval postdose on day 1 (first dose) and day 10 (last dose) are displayed in figure 8 . No relevant change from day 1 to day 10 was observed in subjects administered placebo $(29.6 \pm 12.4 \mu \mathrm{g}$ on day $10 \mathrm{vs}$ $33.1 \pm 10.5 \mu \mathrm{g}$ on day 1$)$. Following repeated etamicastat administration, urinary excretion of norepinephrine decreased, which is consistent with the claimed $\mathrm{D} \beta \mathrm{H}$ inhibitory effect of etamicastat. In relation to the day 1 value, urinary excretion of norepinephrine at day 10 decreased by $24 \%, 18 \%$, $36 \%, 34 \%, 32 \%$, and $34 \%$ following repeated administration of etamicastat 25, 50, 100, 200, 400, and $600 \mathrm{mg}$, respectively. No relevant changes were found in the urinary excretion of homovanillic acid, epinephrine and dopamine in the different dose groups.

Due to the expected pharmacologic effect of etamicastat, supine SBP, DBP, and ECG-measured heart rate (HR) measurements were considered as pharmacodynamic variables. Following the first dose of placebo or etamicastat 25, 50, 100, 200, 400 , and $600 \mathrm{mg}$, no significant changes in SBP, DBP, or HR were observed. Following repeated dosing, SBP and HR did not significantly change at any dose levels, but a significant decrease in DBP occurred with etamicastat $100 \mathrm{mg}$ and $200 \mathrm{mg}$ doses. In relation to day $1, \mathrm{DBP} \mathrm{E}_{\max }$ and $\mathrm{AUC}_{\mathrm{EC}}$ decreased by $5.6 \mathrm{mmHg}(\mathrm{p}<0.01)$ and $223 \mathrm{mmHg} \bullet \mathrm{h}$ $(\mathrm{p}<0.05)$ following etamicastat $100 \mathrm{mg}$ and by $5.9 \mathrm{mmHg}(\mathrm{p}<0.05)$ and $193 \mathrm{mmHg} \bullet \mathrm{h}(\mathrm{p}<0.05)$ following etamicastat $200 \mathrm{mg}$, respectively.

Table V. Proportionality of maximum concentration $\left(C_{\max }\right)$ and area under the plasma concentration-time curve from time 0 to 24 hours $\left(\mathrm{AUC}_{24}\right)$ of etamicastat and BIA 5-961 following the first dose (day 1) and the final dose (day 10) of repeated administration of etamicastat to healthy subjects

\begin{tabular}{|c|c|c|c|c|c|c|c|c|c|}
\hline \multirow{3}{*}{$\begin{array}{l}\text { Etamicastat dose } \\
\text { (mg) }\end{array}$} & \multirow{3}{*}{$\begin{array}{l}\text { Fold } \\
\text { increase in } \\
\text { dose }\end{array}$} & \multicolumn{4}{|c|}{ Etamicastat } & \multicolumn{4}{|l|}{ BIA 5-961 } \\
\hline & & \multicolumn{2}{|c|}{ fold increase in $\mathrm{C}_{\max }$} & \multicolumn{2}{|c|}{ fold increase in $\mathrm{AUC}_{24}$} & \multicolumn{2}{|c|}{ fold increase in $\mathrm{C}_{\max }$} & \multicolumn{2}{|c|}{ fold increase in $\mathrm{AUC}_{24}$} \\
\hline & & first dose & last dose & first dose & last dose & first dose & last dose & first dose & last dose \\
\hline $25(n=6)$ & 1 & 1 & 1 & 1 & 1 & 1 & 1 & 1 & 1 \\
\hline $50(n=6)$ & 2.0 & 2.4 & 2.0 & 2.5 & 2.2 & 1.6 & 1.7 & 1.6 & 1.6 \\
\hline $100(n=6)$ & 2.0 & 2.3 & 2.4 & 2.1 & 2.2 & 1.1 & 2.5 & 1.2 & 1.6 \\
\hline $200(n=12)$ & 2.0 & 2.0 & 1.8 & 2.0 & 1.8 & 1.7 & 1.6 & 1.8 & 1.6 \\
\hline $400(n=6)$ & 2.0 & 2.9 & 2.2 & 1.8 & 1.9 & 3.0 & 2.9 & 2.7 & 2.7 \\
\hline $600(n=6)$ & 1.5 & 1.5 & 1.5 & 1.6 & 1.3 & 2.1 & 1.9 & 2.0 & 1.8 \\
\hline
\end{tabular}




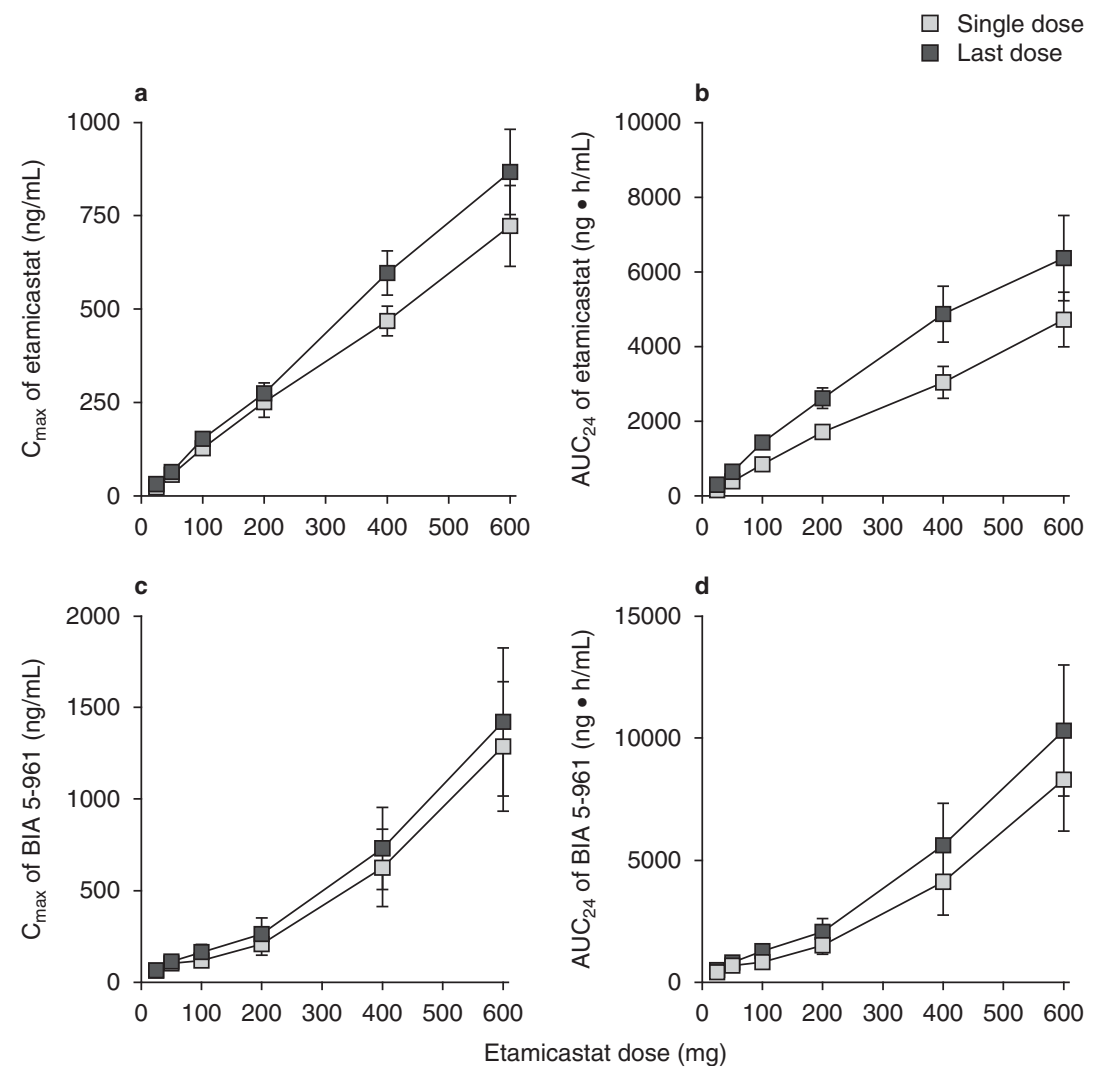

Fig. 5. Maximum plasma concentrations $\left(C_{\max }\right)$ and area under the concentration-time curve from time 0 to 24 hours $\left(A \cup C_{24}\right)$ values (mean \pm SEM) of (a and $\mathbf{b}$ ) etamicastat and (c and d) BIA 5-961 following single (day 1) and repeated (day 10) oral once-daily administration of etamicastat in the dose range 25-600 mg (etamicastat $200 \mathrm{mg}: \mathrm{n}=12$; other dose groups: $n=6$ per dose group).

\section{Discussion}

This trial constituted the second study with etamicastat, a new $\mathrm{D} \beta \mathrm{H}$ inhibitor, in humans. The objectives of the study were to evaluate the safety, tolerability, and pharmacokinetics of etamicastat in healthy male adults following repeated administration. The study followed a standard design commonly used in studies with identical purposes. Etamicastat administered orally at doses up to $600 \mathrm{mg}$ once daily for 10 days appeared to be well tolerated. All AEs were mild to moderate in intensity. Most subjects $(83 \%)$ in the $600 \mathrm{mg}$ etamicastat group reported diarrhea as an AE. Diarrhea has also been reported at high etamicastat doses in preclinical studies. $\mathrm{D} \beta \mathrm{H}$ gene variants that cause low plasma $\mathrm{D} \beta \mathrm{H}$ have also been associated with an increased propensity to report diarrhea. ${ }^{[27]}$ The data show that a marked decrease of $\mathrm{D} \beta \mathrm{H}$ activity can predispose to the occurrence of diarrhea. A papular rash of plausible infectious origin occurred in three subjects under treatment with etamicastat $200 \mathrm{mg}$. There were no serious AEs or clinically significant abnormalities in clinical laboratory tests, vital signs, or ECG parameters.

Consistent with the results from a previous study in which etamicastat single doses of $2-1200 \mathrm{mg}$ were administered to young healthy subjects, ${ }^{[21]}$ etamicastat was shown to be metabolized to its N-acetylated metabolite BIA 5-961 following single and repeated administration of $25-600 \mathrm{mg}$ once-daily doses. $\mathrm{C}_{\max }$ of etamicastat and BIA 5-961 were achieved at 1-3 hours and 2-4 hours after dosing, respectively. Thereafter, etamicastat 


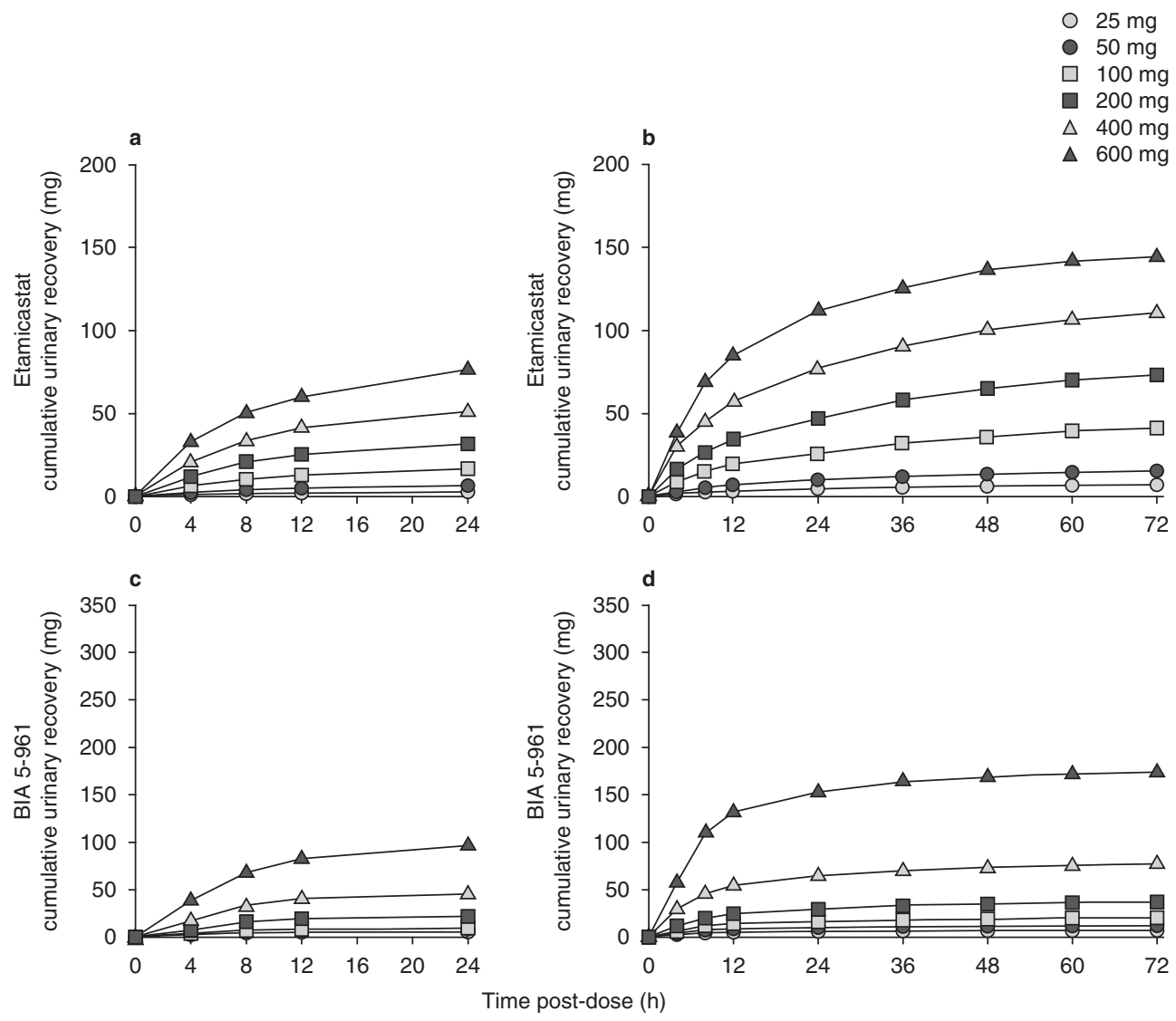

Fig. 6. Mean cumulative urinary excretion of etamicastat following single (day 1 [a]) and repeated (day 10 [b]), and BIA 5-961 following single (day $1[\mathbf{c}]$ ) and repeated (day 10 [d]) oral once-daily administration of etamicastat in the dose range 25-600 mg (etamicastat $200 \mathrm{mg}: \mathrm{n}=12$; other dose groups: $\mathrm{n}=6$ per dose group).

plasma concentrations declined with a mean apparent $t_{1 / 2}$ of $9-15$ hours following the first dose and 18-26 hours following the last dose. Estimated $t_{1 / 2}$ values for BIA 5-961 were slightly shorter than those of the parent drug. Both etamicastat and BIA 5-961 followed approximate linear pharmacokinetics over the dose range studied. The extent of systemic exposure to etamicastat increased in an approximately doseproportional manner following single and repeated administration. Etamicastat accumulated in plasma following repeated administration. The mean $R_{O}$ was 1.3-1.9 for etamicastat and 1.3-1.6 for BIA 5-961. The identical accumulation ratio of BIA $5-961$ is consistent with the slightly shorter $t_{1 / 2}$ of BIA 5-961 compared with that of etamicastat.
Steady-state etamicastat and BIA 5-961 plasma concentrations were reached up to 9 days of etamicastat repeated administration.

Table VI. N-acetyltransferase (NAT)-1 and NAT2 phenotype by etamicastat dose group

\begin{tabular}{lllllll}
\hline \multirow{2}{*}{$\begin{array}{l}\text { Etamicastat dose } \\
\text { (mg) }\end{array}$} & \multicolumn{3}{l}{ No. of subjects } & & & \\
\cline { 2 - 4 } \cline { 6 - 7 } & NAT1 & & & & \\
\cline { 2 - 4 } & slow & normal & fast & & slow & fast \\
\hline $25(n=6)$ & 0 & 4 & 2 & 3 & 3 \\
$50(n=6)$ & 0 & 2 & 4 & 3 & 3 \\
$100(n=6)$ & 0 & 4 & 2 & 3 & 3 \\
$200(n=12)$ & 0 & 6 & 6 & 7 & 5 \\
$400(n=6)$ & 1 & 4 & 1 & 1 & 5 \\
$600(n=6)$ & 1 & 1 & 4 & 4 & 2 \\
\hline
\end{tabular}


Approximately $45 \%$ of the etamicastat dose was recovered in urine collected up to 24 hours post-dose in the form of parent drug and $\mathrm{N}$ acetylated metabolite. These data are consistent with those from a study aiming to characterize the absorption, distribution, metabolism, and excretion of etamicastat and metabolites following an oral dose of $\left[{ }^{14} \mathrm{C}\right]$-labeled etamicastat (BIAL unpublished observation). Eleven days after administration, approximately $95 \%$ of the administered radioactivity had been excreted, two-thirds in urine and one-third in feces. Biotransformation of etamicastat occurred mainly via $\mathrm{N}$-acetylation, forming BIA 5-961, the major metabolite. However, glucuronidation, oxidation, oxidative deamination, and de-sulfation were also involved.
Renal clearance of etamicastat from plasma following repeated oral administration of etamicastat was $11.9-16.0 \mathrm{~L} / \mathrm{h}$, which is higher than the glomerular filtration rate $(7.6 \mathrm{~L} / \mathrm{h})$.

$\mathrm{N}$-Acetylation is the major metabolic pathway for etamicastat. Humans express two functional NAT isoforms, NAT1 and NAT2. NAT1 has broad tissue distribution whereas NAT2 is more restricted, with higher levels of expression in the liver and red blood cells. ${ }^{[23]}$ NAT exhibits different substrate specificities. Human NAT1 and NAT2 loci are highly polymorphic, with more than 25 alleles identified in each locus. ${ }^{[28,29]}$ Within this polymorphic population, different phenotypes have been identified for both forms, NAT1 and NAT2. As an important metabolizing en-
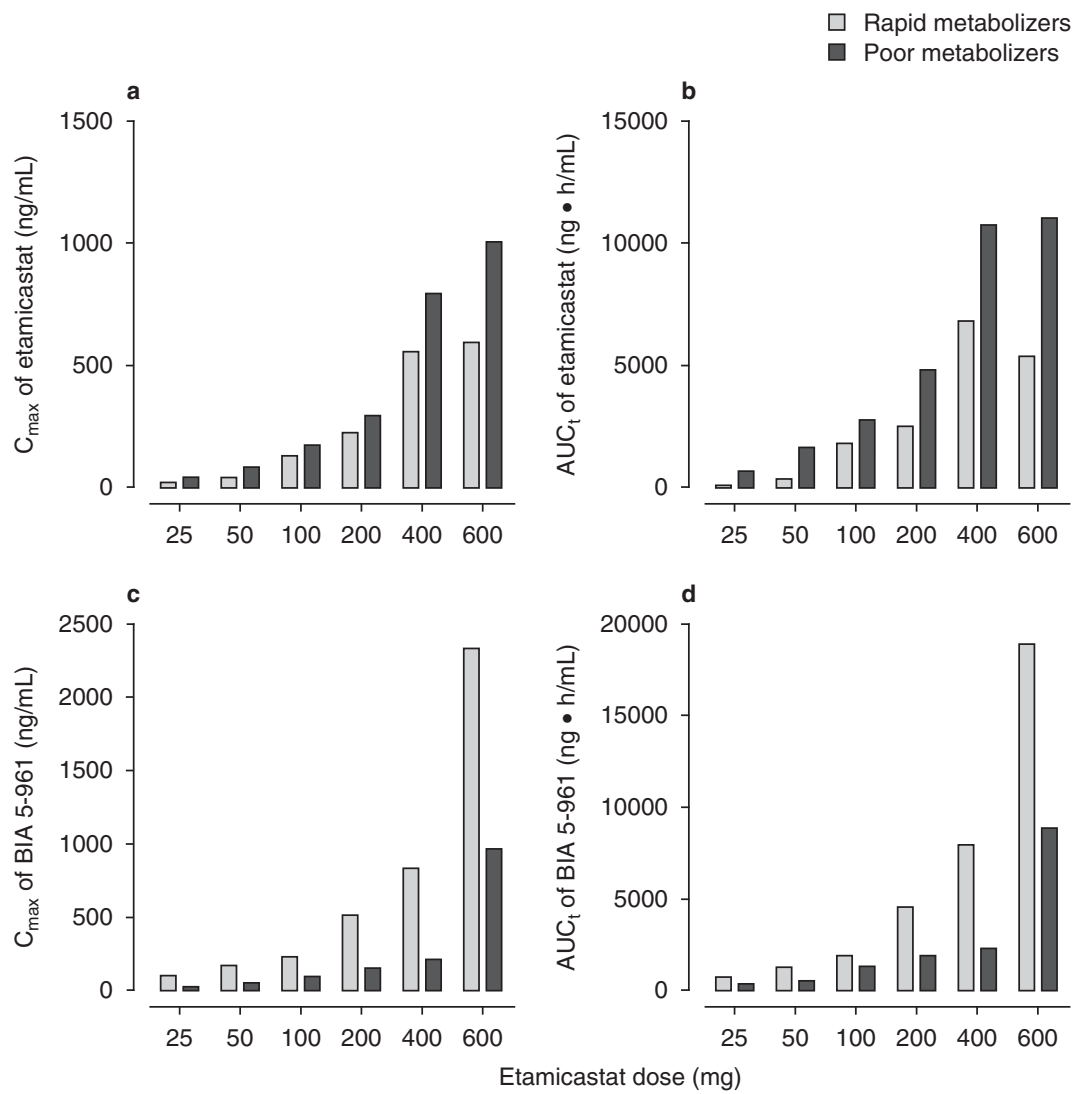

Fig. 7. Mean maximum plasma concentrations $\left(C_{\max }\right)$ and area under the concentration-time curve from time zero to the last sampling time at which concentrations were at or above the limit of quantification $\left(A \cup C_{t}\right)$ of $(\mathbf{a}$ and $\mathbf{b}$ ) etamicastat and (c and d) BIA 5-961 in rapid or poor $\mathrm{N}$-acetyltransferase-2 acetylators following single (day 1 ) and repeated (day 10) oral once-daily administration of etamicastat in the dose range 25-600 mg (etamicastat $200 \mathrm{mg}: \mathrm{n}=12$; other dose groups: $n=6$ per dose group). 


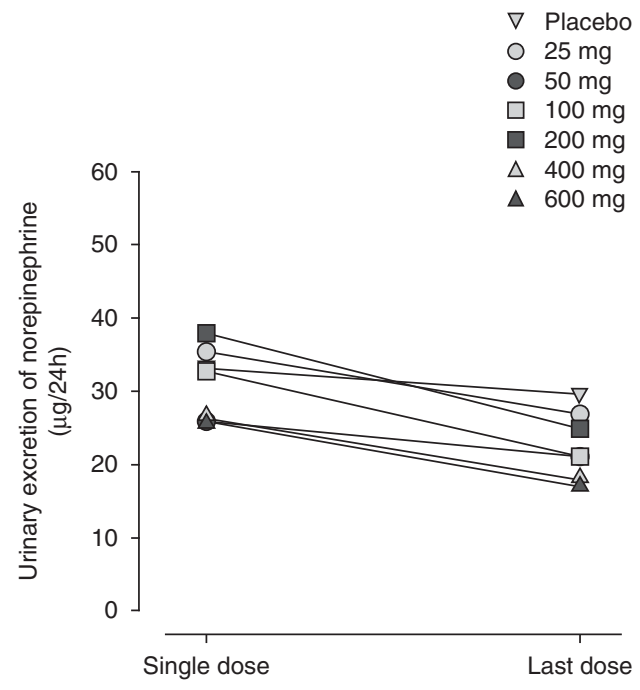

Fig. 8. Mean cumulative urinary excretion of norepinephrine (noradrenaline) during a 24-hour period following the first (day 1 ) and last (day 10) doses of a once-daily regimen of placebo and etamicastat in the dose range 25-600 $\mathrm{mg}$ (placebo: $\mathrm{n}=14$; etamicastat $200 \mathrm{mg}$ : $n=12$; other dose groups: $n=6$ per dose group).

zyme in humans, the polymorphism of human NAT expression, especially NAT2, raises concerns about drug-drug interactions during clinical use. In in vitro studies (BIAL unpublished observation), etamicastat $\mathrm{N}$-acetylation in cytosolic fraction showed a good correlation with sulfamethazine NAT activity, a selective substrate to NAT2, but not with $p$-aminosalicylic acid, a selective substrate to NAT1, suggesting that etamicastat $\mathrm{N}$-acetylation is predominantly driven by NAT2. These data are consistent with the results from the current study and those of a previous single-dose study in healthy subjects, ${ }^{[21]}$ which showed no apparent major influence of NAT1 phenotype on etamicastat pharmacokinetics. However, the contribution of NAT1 to etamicastat metabolism should not be completely excluded, since NAT2 is expressed predominantly in liver whereas NAT1 is expressed ubiquitously. ${ }^{[23]}$

As demonstrated in figure 7 , the extent of systemic exposure to etamicastat differed markedly between NAT2 poor and rapid acetylators. The extent of systemic exposure to etamicastat in NAT2 poor acetylators was 1.5-6.7 times higher than that observed in rapid acetylators and, inversely, NAT2 rapid acetylators showed a 1.5- to 3.5-fold increase in systemic exposure to the $\mathrm{N}$ acetylated metabolite, confirming the involvement of NAT2 in the biotransformation of etamicastat into BIA 5-961. The magnitude of the effect of NAT2 phenotype on etamicastat pharmacokinetics is a strong argument for genotyping participants in further clinical trials with etamicastat. Effective clinical translation would establish etamicastat pharmacogenomics as a step toward personalized medicine for etamicastat.

Similar to a previous single-dose study, ${ }^{[21]}$ the distribution of fast and slow NAT2 acetylators was not equal in all dose groups in the current study, and differences in the proportion of NAT2 fast/slow acetylators complicated the interpretation of the results (i.e. the dose-proportionality assessment) and were a cause of variability. To facilitate the interpretation of the results, stratification according to NAT2 phenotype could be considered in future studies with etamicastat.

$\mathrm{D} \beta \mathrm{H}$ catalyzes the conversion of dopamine into norepinephrine. Consistently with the claimed $\mathrm{D} \beta \mathrm{H}$ inhibitory effect by etamicastat, urinary excretion of norepinephrine decreased following repeated administration of etamicastat. For doses of etamicastat $100 \mathrm{mg}$ and above, the decrease in norepinephrine urinary excretion was $32-36 \%$. It should be taken into account, however, that the reported effect may be underestimated, since day 1 values do not correspond to a true baseline because they might have been influenced by the effect of the first dose of etamicastat. No relevant change from day 1 to day 10 was found in the other urinary catecholamines in the different dose groups.

A statistically significant decrease was found in supine DBP following repeated administration of etamicastat $100 \mathrm{mg}$ and $200 \mathrm{mg}$. Although consistent with the claimed pharmacologic effect, this effect, however, should be interpreted with caution because no clear dose-response relationship was observed and the number of subjects in each dose group is small.

\section{Conclusions}

In conclusion, etamicastat was well tolerated and was shown to be metabolized to the 
$\mathrm{N}$-acetylated metabolite BIA 5-961, following single and multiple doses of etamicastat $25-600 \mathrm{mg}$. Etamicastat and its metabolite followed linear pharmacokinetics, and steady-state plasma concentrations were attained up to 9 days of dosing. Etamicastat pharmacokinetics are markedly affected by the NAT2 phenotype, and NAT2 genotyping could be a step toward personalized medicine for etamicastat. Consistently with the expected pharmacologic effect, urinary excretion of norepinephrine decreased following repeated administration of etamicastat.

\section{Acknowledgments} The

This trial was sponsored by BIAL (Portela and Co, S.A., $\mathrm{S}$. Mamede do Coronado, Portugal). The authors from BIAL substantially contributed to the design and conception of the study and wrote the first and final versions of the manuscript, but played no role in data collection or pharmacokinetic analysis. All authors had full access to the data and substantially contributed to the interpretation of the data and the writing of the manuscript.

TN, JFR, MVS, BI, LCW, LA, and PSS are or were employees of BIAL (the sponsor of the study) at the time of the study. The other author (AF) is or was an employee of a contract research organization contracted by the sponsor to review the pharmacokinetic data (4Health).

\section{References}

1. Esler M, Kaye D. Sympathetic nervous system activation in essential hypertension, cardiac failure and psychosomatic heart disease. J Cardiovasc Pharmacol 2000; 35 (7 Suppl. 4): S1-7

2. Grassi G, Bolla G, Quarti-Trevano F, et al. Sympathetic activation in congestive heart failure: reproducibility of neuroadrenergic markers. Eur J Heart Fail 2008 Dec; 10 (12): 1186-91

3. Grassi G, Seravalle G, Quarti-Trevano F. The 'neuroadrenergic hypothesis' in hypertension: current evidence. Exp Physiol 2010 Dec 11; 95 (5): 581-6

4. Lee CS, Tkacs NC. Current concepts of neurohormonal activation in heart failure: mediators and mechanisms. AACN Adv Crit Care 2008 Oct-Dec; 19 (4): 364-85

5. Mancia G, Grassi G, Giannattasio C, et al. Sympathetic activation in the pathogenesis of hypertension and progression of organ damage. Hypertension 1999; 34 (4 Pt 2): 724-8

6. Parmley WW. Neuroendocrine changes in heart failure and their clinical relevance. Clin Cardiol 1995; 18 (8): 440-5

7. Pfeffer MA, Stevenson LW. Beta-adrenergic blockers and survival in heart failure. N Engl J Med 1996; 334 (21): 1396-7
8. Stanley WC, Li B, Bonhaus DW, et al. Catecholamine modulatory effects of nepicastat (RS-25560-197), a novel, potent and selective inhibitor of dopamine-beta-hydroxylase. Br J Pharmacol 1997; 121 (8): 1803-9

9. Hegde SS, Friday KF. Dopamine-beta-hydroxylase inhibition: a novel sympatho-modulatory approach for the treatment of congestive heart failure. Curr Pharm Des 1998; 4 (6): 469-79

10. Soares-da-Silva P. Evidence for a non-precursor dopamine pool in noradrenergic neurones of the dog mesenteric artery. Naunyn Schmiedebergs Arch Pharmacol 1986 Jul; 333 (3): 219-23

11. Soares-da-Silva P. A comparison between the pattern of dopamine and noradrenaline release from sympathetic neurones of the dog mesenteric artery. Br J Pharmacol 1987 Jan; 90 (1): $91-8$

12. Gomes P, Soares-da-Silva P. Dopamine. In: Baden M, editor. Cardiovascular hormone systems: from molecular mechanisms to novel therapeutics. Weinheim: Wiley-VCH, 2008: 251-93

13. Jose PA, Eisner GM, Felder RA. Role of dopamine receptors in the kidney in the regulation of blood pressure. Curr Opin Nephrol Hypertens 2002 Jan; 11 (1): 87-92

14. Ishii $Y$, Fujii $Y$, Mimura $C$, et al. Pharmacological action of FD-008, a new dopamine beta-hydroxylase inhibitor: I, effects on blood pressure in rats and dogs. Arzneimittelforschung 1975; 25 : 55-9

15. Kruse LI, Kaiser C, DeWolf Jr WE, et al. Multisubstrate inhibitors of dopamine beta-hydroxylase: 2 , structureactivity relationships at the phenethylamine binding site. J Med Chem 1987; 30: 486-94

16. Ohlstein EH, Kruse LI, Ezekiel M, et al. Cardiovascular effects of a new potent dopamine beta-hydroxylase inhibitor in spontaneously hypertensive rats. J Pharmacol Exp Ther 1987; 241: 554-9

17. Beliaev A, Learmonth DA, Soares-da-Silva P. Synthesis and biological evaluation of novel, peripherally selective chromanyl imidazolethione-based inhibitors of dopamine betahydroxylase. J Med Chem 2006; 49 (3): 1191-7

18. Kruse LI, Kaiser C, DeWolf Jr WE, et al. Substituted 1benzylimidazole-2-thiols as potent and orally active inhibitors of dopamine beta-hydroxylase. J Med Chem 1986; 29: $887-9$

19. Igreja B, Wright L, Soares-Da-Silva P. Sustained antihypertensive effects of a selective peripheral dopamine- $\beta$ hydroxylase inhibitor [abstract]. Hypertension 2007; 50: e133

20. Beliaev A, Ferreira H, Learmonth DL, et al. Dopamine beta-monooxygenase: mechanism, substrates and inhibitors. Curr Enzyme Inh 2009; 5: 27-43

21. Nunes T, Rocha JF, Almeida L, et al. A rising single oral dose study to investigate the tolerability and pharmacokinetics of etamicastat, a new dopamine beta-hydroxylase inhibitor, in healthy male volunteers [abstract]. J Clin Pharmacol 2009; 49: 1094

22. Falcao A, Nunes $\mathrm{T}$, Rocha JF, et al. Comparative bioavailability study of etamicastat (BIA 5-453) under fasted and fed conditions [abstract]. J Clin Pharmacol 2009; 49: 1095 
23. Winter HR, Unadkat JD. Identification of cytochrome P450 and arylamine $\mathrm{N}$-acetyltransferase isoforms involved in sulfadiazine metabolism. Drug Metab Dispos 2005; 33: $969-76$

24. Fronhoffs S, Bruning T, Ortiz-Pallardo E, et al. Real-time PCR analysis of the N-acetyltransferase NAT1 allele *3, $* 4, * 10, * 11, * 14$ and $* 17$ polymorphism in squamous cell cancer of head and neck. Carcinogenesis 2001 Sep; 22 (9): 1405-12

25. Brocvielle H, Muret $\mathrm{P}$, Goydadin AC, et al. N-acetyltransferase 2 acetylation polymorphism: prevalence of slow acetylators does not differ between atopic dermatitis patients and healthy subjects. Skin Pharmacol Appl Skin Physiol 2003 Nov-Dec; 16 (6): 386-92

26. Rychlik-Sych M, Skretkowicz J, Gawronska-Szklarz B, et al. Acetylation genotype and phenotype in patients with systemic lupus erythematosus. Pharmacol Rep 2006 JanFeb; 58 (1): 22-9
27. Deinum J, Steenbergen-Spanjers GC, Jansen M, et al. DBH gene variants that cause low plasma dopamine beta hydroxylase with or without a severe orthostatic syndrome [letter]. J Med Genet 2004 Apr; 41 (4): e38

28. Walraven JM, Zang Y, Trent JO, et al. Structure/function evaluations of single nucleotide polymorphisms in human N-acetyltransferase 2. Curr Drug Metab 2008 Jul; 9 (6): 471-86

29. Walraven JM, Trent JO, Hein DW. Structure-function analyses of single nucleotide polymorphisms in human $\mathrm{N}$ acetyltransferase 1. Drug Metab Rev 2008; 40 (1): 169-84

Correspondence: Professor Patricio Soares-da-Silva, Department of Research and Development, BIAL, À Av. da Siderurgia Nacional, 4745-457 S. Mamede do Coronado, Portugal.

E-mail: psoares.silva@bial.com 